\title{
Technical Note: Determination of the metabolically active fraction of benthic foraminifera by means of Fluorescent In Situ Hybridization (FISH)
}

\author{
C. Borrelli ${ }^{1, *}$, A. Sabbatini ${ }^{1}$, G. M. Luna ${ }^{1}$, M. P. Nardelli ${ }^{1}$, T. Sbaffi ${ }^{1}$, C. Morigi ${ }^{2}$, R. Danovaro ${ }^{1}$, and A. Negri ${ }^{1}$ \\ ${ }^{1}$ Dipartimento di Scienze della Vita e dell'Ambiente, Polytechnic University of Marche, Via Brecce Bianche, \\ 60122 Ancona, Italy \\ ${ }^{2}$ Stratigraphy Department, Geological Survey of Denmark and Greenland (GEUS), Øster Voldgade 10, \\ 1350 Copenhagen K, Denmark \\ *current address: Department of Earth and Environmental Sciences, Rensselaer Polytechnic Institute, 110 8th Street, Troy, \\ NY, 12180, USA
}

Received: 1 October 2010 - Published in Biogeosciences Discuss.: 13 October 2010

Revised: 27 July 2011 - Accepted: 29 July 2011 - Published: 4 August 2011

\begin{abstract}
Benthic foraminifera are an important component of the marine biota, but protocols for investigating their viability and metabolism are still extremely limited. Classical studies on benthic foraminifera have been based on direct counting under light microscopy. Typically, these organisms are stained with Rose Bengal, which binds proteins and other macromolecules, but does not allow discrimination between viable and recently dead organisms. The fluorescent in situ hybridization technique (FISH) represents a new and useful approach to identify living cells possessing an active metabolism. Our work is the first test of the suitability of the FISH technique, based on fluorescent probes targeting the 18S rRNA, to detect live benthic foraminifera. The protocol was applied on Ammonia group and Miliolids, as well as on agglutinated polythalamous (i.e., Leptohalysis scottii and Eggerella scabra) and soft-shelled monothalamous (i.e., Psammophaga sp. and saccamminid morphotypes) taxa. The results from FISH analyses were compared with those obtained, on the same specimens assayed with FISH, from microscopic analysis of the cytoplasm colour, presence of pigments and pseudopodial activity. Our results indicate that FISH targets only metabolically active foraminifera, and allows discerning from low to high cellular activity, validating the hypothesis that the intensity of the fluorescent signal emitted by the probe is dependent upon the physiological status of cells. These findings support the usefulness of this molecular approach as a key tool for obtaining information on the physiology of living foraminifera, both in field and experimental settings.
\end{abstract}

Correspondence to: C. Borrelli (borrec@rpi.edu)

\section{Introduction}

Foraminifera is a group of testate protists, which in deepsea ecosystems can become a dominant component of the benthic fauna, both in terms of abundance and biomass (Gooday et al., 1998). Since hard-shelled foraminifera (foraminifera with a calcareous or a multilocular agglutinated test) are largely used for paleoenvironmental reconstructions, the knowledge of the fossil assemblages is quite advanced (e.g., Schmiedl and Mackensen, 1997; Katz et al., 2003; Morigi et al., 2005; Murray, 2006; Morigi, 2009). However, current biological and ecological studies are still limited by the lack of reliable protocols to distinguish living from dead foraminifera within the benthic assemblages and to study their metabolism.

Over the last 20 years, new methods have therefore been developed to discern between living and dead foraminifera, each one having a different degree of accuracy and based on a different rationale (Bernhard, 2000). Rose Bengal (RB), a non-vital staining, has been widely used in ecological studies to recognize presumably dead (unstained) foraminifera from the living (stained) counterparts (Walton, 1953; Murray and Bowser, 2000). Other approaches to detect metabolically active foraminifera are based on the use of fluorogenic probes (e.g., diacetates of fluorescein -FDA- and AMesters of biscarboxyethylcarboxyfluorescein -BCECF-AM-; Bernhard et al., 1995) that both measure enzymatic activity, which is required to activate their fluorescence, and cellmembrane integrity. Also, the use of the enzymatic reduction of the MTT salt (3-(4,5-dimethyl-2-thiazolyl)-2,5-diphenyl$2 \mathrm{H}$-tetrazolium bromide or thiazolyl blue, which produces a reddish purple crystal) has been recently proposed as a

Published by Copernicus Publications on behalf of the European Geosciences Union. 
viability assay for living foraminiferal specimens from shallow water systems (de Nooijer et al., 2006). Other probes, such as CellTracker Green CMFDA (CTG), allow detecting actively metabolizing foraminifera by identifying the presence of respiratory activity, either in the laboratory or in situ (Bernhard et al., 2004, 2006; Pucci et al., 2009).

Fluorescent In Situ Hybridization (FISH) is a novel molecular technique, never before utilized in foraminiferal studies, based on the use of fluorescently-labeled, rRNA-targeted oligonucleotide probes, which hybridize target molecules and are later visualized under epifluorescence microscopy. This technique targets the rRNA inside living cells. rRNA is the product of DNA transcription and a component of ribosomes, which are contained in living and actively metabolizing cells, as they perform protein synthesis. FISH involves the use of oligonucleotide probes, which penetrate inside the cell and specifically hybridize the target rRNA sequences in the ribosomes. If there are no target sequences in the ribosomes, the probes will not hybridize and will be eliminated by a subsequent washing step. Probes are labeled with an appropriate fluorochrome and cells containing the hybridized probes can be easily observed under an epifluorescence microscope equipped with appropriate filters. A higher number of ribosomes inside the cell, which is dependent upon the physiological status of cells, means a higher number of rRNA molecules. During FISH hybridization, each single probe will theoretically hybridize with a single molecule of rRNA. Therefore, it is expected that the larger the number of ribosomes in the cell, the stronger the fluorescence will be. As a result, the intensity of the FISH signal can be taken as an indicator of cellular metabolic activity. Moreover, each cell will show a nearly homogenous fluorescence signal, depending on the concentration and localization of ribosomes inside the cell.

The use of the FISH approach for identifying metabolically active cells, here defined as cells possessing a high number of rRNA-containing ribosomes, has been common in prokaryotic ecology for a decade (Karner and Fuhrman, 1997; Christensen et al., 1999). In this contest, it has been widely used in a variety of habitats, including marine sediments and soils, to study Bacteria and Archaea targeting the 16S rRNA (Hugenholtz et al., 2001; Dupperon et al., 2005; Danovaro et al., 2009). FISH, based on $18 \mathrm{~S}$ rRNA as a target molecule, has been applied to eukaryotic single-cell taxa (marine picoeukaryotes, Not et al., 2002; ciliates, such as Uronema sp., flagellates, nanoflagellates and mixed protists assemblages; Lim et al., 1993, 1996: Rice et al., 1997a, 1997b; Fried et al., 2002), photosyntetic protists (Medlin and Kooistra, 2010) and to eukaryotic symbionts of marine invertebrates (e.g., Symbiodinium spp., Yokouchi et al., 2003). At least theoretically, protists are potentially more appropriate for the use of oligonucleotide probes than prokaryotes, because they contain a higher number of ribosomes (up to hundreds of thousands per eukaryotic cell versus 1000-10000 in a bacterial cell) and higher concentrations of rRNA. A further development of FISH targeting marine eukaryotes is represented by the COD-FISH, which enables identification of calcifying microorganisms (Frada et al., 2006). Morever, the combination of SEM and FISH analyses has been shown to largely improve the potential of taxonomic and morphological characterization of a wide range of protists (e.g., alveolates, stramenopiles, kinetoplastids and cryptomonads; Stoeck et al., 2003). Despite the wide potential application of this technique to foraminiferal ecology, a FISH protocol has never been set up and tested to distinguish metabolically active foraminifera in sediments and/or cultures.

In this study, we establish a new protocol, based on FISH targeting the 18S rRNA, to detect and quantify metabolically active foraminifera in experimental sets and marine sediments.

\section{Materials and methods}

\subsection{Sediment sampling and foraminiferal maintenance under controlled conditions}

All foraminifera tested for FISH were extracted from our experimental sets and/or from natural sediment samples. Sediments were collected from two coastal sites (Falconara and Portonovo) located in the Central Adriatic Sea, in October 2009, February 2010 and December 2010, using a Van Veen grab onboard the research boat Actea. Samples were collected at depths of $\sim 5 \mathrm{~m}$ (Falconara) and at a depth of $\sim 15 \mathrm{~m}$ (Portonovo site). Water temperatures at the field sites were $14.4^{\circ} \mathrm{C}$ and $15^{\circ} \mathrm{C}$, respectively, in October; $6.2^{\circ} \mathrm{C}$ and $6.3^{\circ} \mathrm{C}$, respectively, in February. In December 2010, samples were collected only in Portonovo and water temperature was $11.1^{\circ} \mathrm{C}$. The sediment was stored into a plastic box filled with seawater (collected from the same site of the sample) and carried to the laboratory within $2-4 \mathrm{~h}$, where it was immediately processed. Only the top $2 \mathrm{~cm}$ of the sediment, containing the highest abundance of living foraminifera (Gooday, 1996; de Stigter et al., 1998; Bernhard et al., 2008), was collected.

For cultures, sediments were stored at in situ temperature and salinity (36, constant during the sampling) and immediately transferred to the laboratory to reduce possible stress to the organisms. Two culture sets were prepared in airtight boxes. During growth, chemical and physical parameters were maintained at a $\mathrm{pH}$ of 8 , temperature of $23^{\circ} \mathrm{C}$ and salinity of 36. To measure salinity, we used a refractometer (MR100ATC, Milwaukee, resolution of \pm 0.001 ). Salinity was measured on a scale of $0-100$, after the instrument calibration with distilled water. $\mathrm{pH}$ values were measured with a pH meter (Hanna Instruments, HI98127, electrode HI73127) and expressed on the NBS scale. This instrument utilizes an electrode to measure $\mathrm{pH}$ values after a calibration with two solutions, one at a $\mathrm{pH}$ of 4.01 and another one at a $\mathrm{pH}$ of 7.01. After that, $\mathrm{pH}$ readings were automatically temperature 


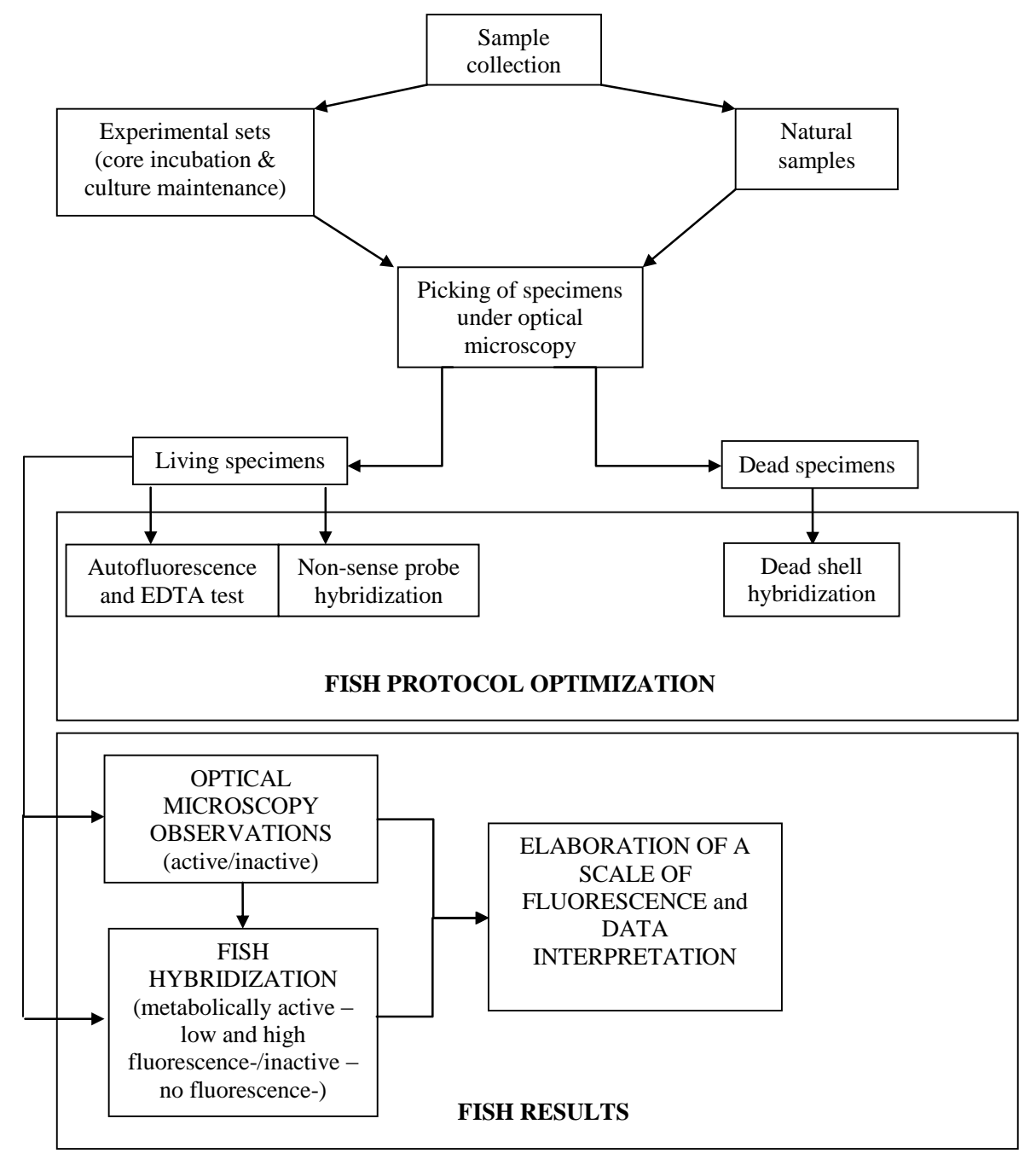

Fig. 1. General scheme of the experimental design to test our FISH protocol. See text for details.

$\left({ }^{\circ} \mathrm{C}\right)$ compensated and expressed on a scale from -2.0 to $16.0 \mathrm{pH}$, with a resolution of 0.1 and an accuracy of \pm 0.1 . To avoid evaporation and to maintain stable salinity within the cultures, small quantities of filtered $(0.45 \mu \mathrm{m})$ seawater, properly mixed with distilled water, were added every week. Cultures were fed, every two weeks, with a mixture of algae (Dunaliella parva, Chlorella sp. and Isochrysis sp., Heinz, 2001; Heinz et al., 2001). Prior to injection in the cultures, the algae were treated in an ultrasound bath.

Samples collected in December 2010 were immediately processed for FISH analyses. Finally, additional specimens were picked after 7 weeks without feeding from cores collected at Portonovo in December 2010 and incubated at $\mathrm{pH}<8$, temperature of $17^{\circ} \mathrm{C}$ and salinity of 30 .

\subsection{FISH: protocol and optimization}

To develop a FISH protocol that could be used on foraminifera, we adapted the protocol routinely used for marine Bacteria and Archaea and other microbial eukaryotes, such as ciliates and dinoflagellates (Karner and Fuhrman, 1997; Hugenholtz et al., 2001; Not et al., 2002; Stoeck et al., 2003; Yokouchi et al., 2003; Mikulski et al., 2005; Frada et al., 2006). To test the efficiency of FISH over different foraminiferal taxonomic groups, we selected specimens of the most represented species in coastal marine sediments. For this reason, we used organisms belonging to the calcareous Ammonia group and Miliolids, to agglutinated species (such as Leptohalysis scottii and Eggerella scabra) and to soft-shelled monothalamous undetermined species (e.g., Psammophaga sp. and Silver saccamminid sp., Fig. 3 in Gooday et al., 2005; Saccamminid sp. 8, Plate 2 in Sabbatini et al., 2010; and Saccamminid sp. 2, Fig. 6a-c 

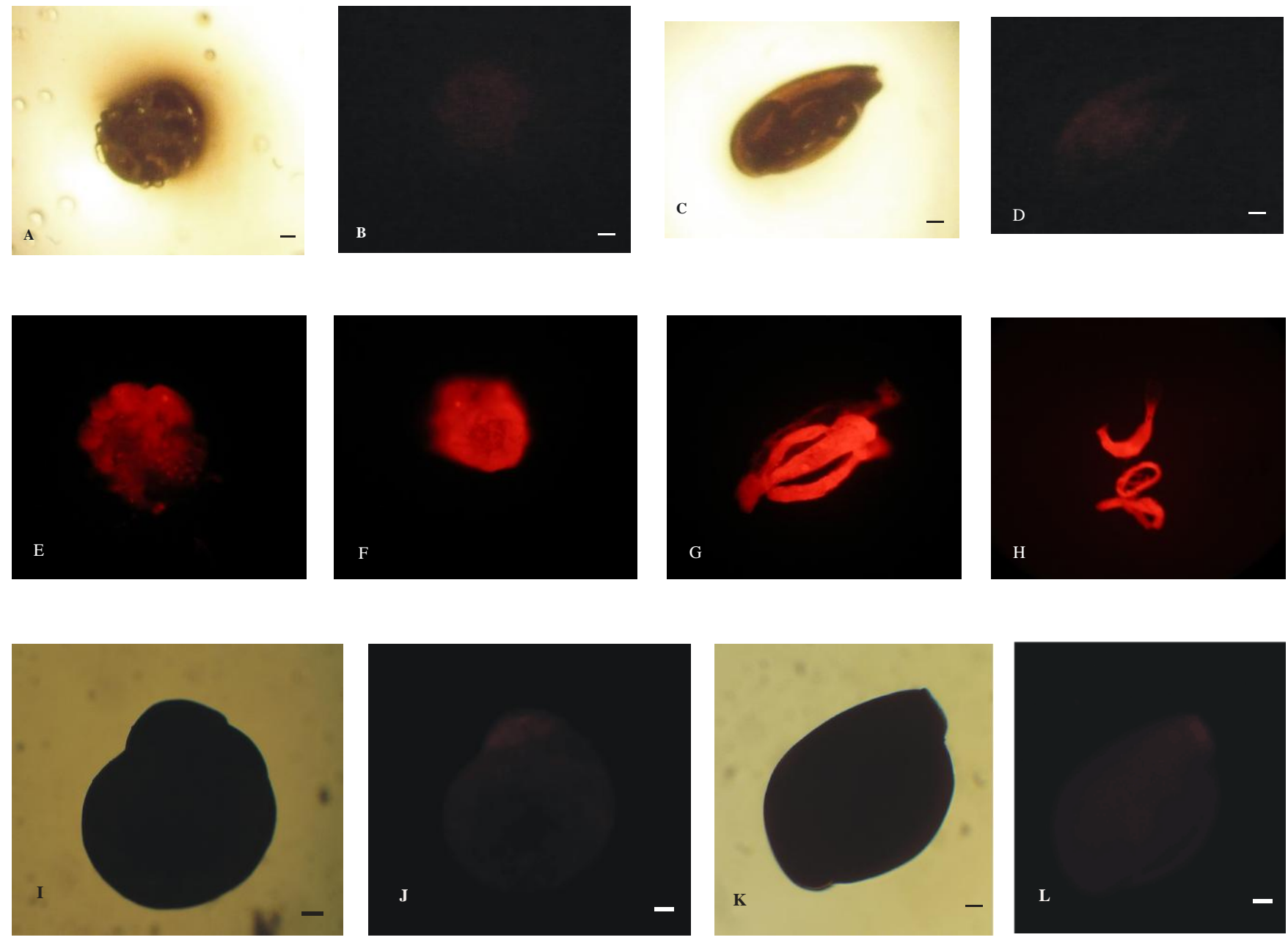

Fig. 2. Results of the experiments carried out to optimize the FISH protocol. (A)-(D) FISH performed on foraminiferal tests after removal of organic material in order to test the possibility of an hybridization between the FISH probe and some components of the shell. (A)(B) Ammonia sp.; analyzed under optical microscopy (A) and epifluorescence microscopy (B) after hybridization with the S17 probe; (C)-(D) Miliolids group individual analyzed under optical microscopy (C)) and epifluorescence microscopy (D) after hybridization with the S17 probe. (E)-(H) FISH performed on foraminiferal hard shells after EDTA fixation in order to test the possibility of hybridization between FISH probes and some components of the shell. (E)-(F) Ammonia sp. analyzed by epifluorescence microscopy after EDTA treatment and hybridization with the S17 probe $(\mathbf{E})$ and EUK 1209 probe $(\mathbf{F})$; (G)-(H) Miliolids group individuals viewed under epifluorescence microscopy after EDTA treatment and hybridization with the S17 probe (G) and EUK 1209 probe (H). (I)-(L) FISH performed with nonsense probes to verify a possible non-specific probe binding during in situ hybridization. (I)-(J) Ammonia sp. analyzed using optical (I) and epifluorescence (J) microscopy. (K)-(L) Individual from the Miliolids group viewed under optical (K) and epifluorescence (L) microscopy. See text for details. Scale bars $=12.5 \mu \mathrm{m}$, except where stated.

in Gooday et al., 2004). To optimize the procedure, we compared two oligonucleotide probes: (1) EUK 1209R (5' GGGCATCACAGACCTG- $3^{\prime}$ ), which is a widely used universal eukaryotic probe already utilized for FISH analysis (Lim et al., 1993; Not et al., 2002; Stoeck et al., 2003); and (2) S17 (5'-CGGTCACGTTCGTTGC-3'), a probe specifically designed for foraminifera and previously used for phylogenetic analyses within this group (Pawlowski, 2000; Holzmann et al., 2001; Pawlowski and Holzmann, 2002; Garcia-Cuetos et al., 2005). According to Pernthaler et al. (2001) and Hugenholtz et al. (2001), selected foraminifera were also treated during each FISH session with non-sense probes "non-EUK 1209R" and "non-S17", representing the reverse complement of the probes EUK 1209R and S17 (Fig. 1). These probes are negative controls of FISH assay, not having any known rRNA target, and were used to check for the non-specific incorporation of the probe into the cells during hybridization. None of the cells hybridized with non-sense probes showed fluorescence emission (see the Results section; Fig. 2), which clearly demonstrated that nonspecific probe binding did not occur during in situ hybridization analysis. 

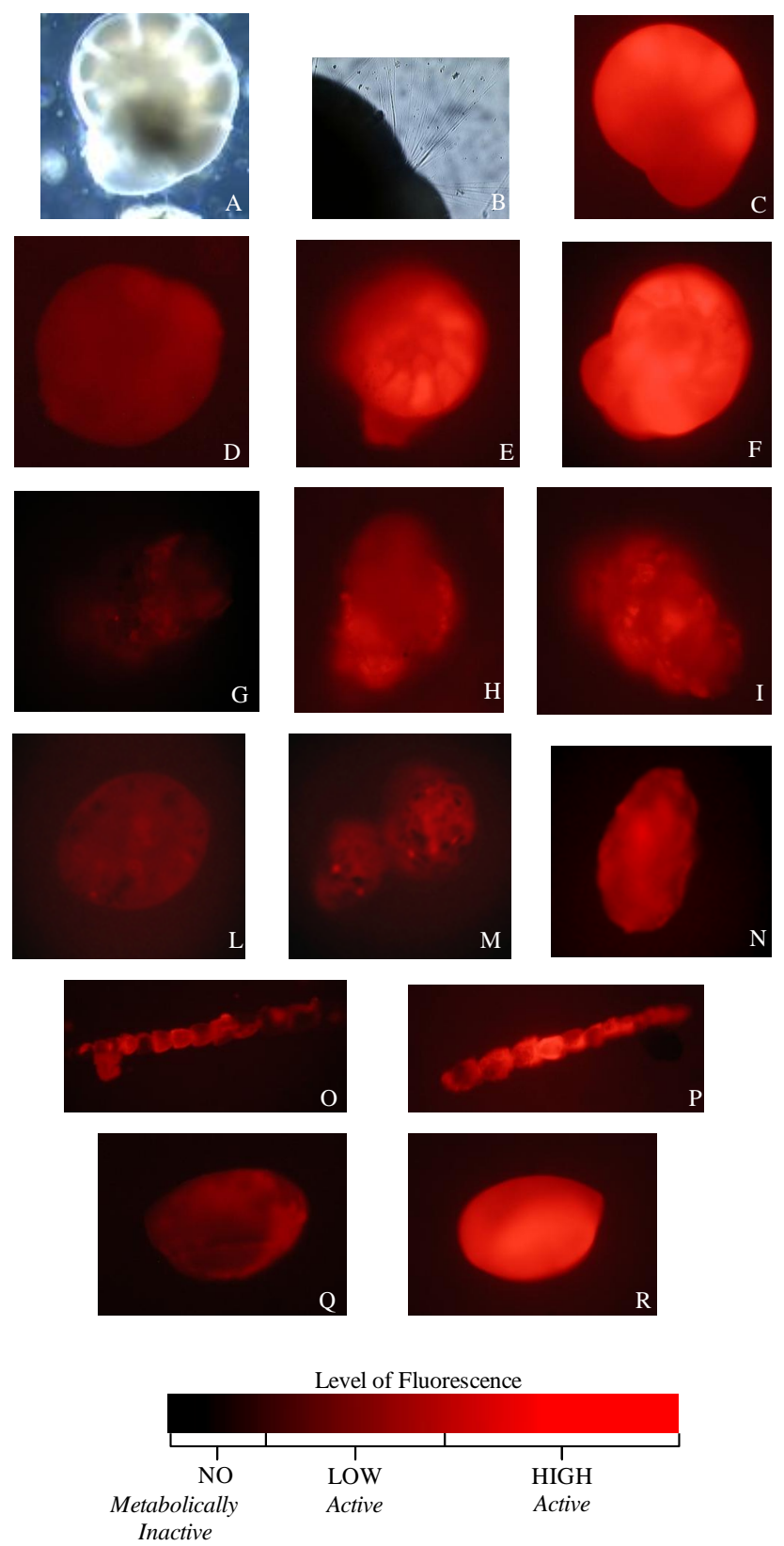

Fig. 3. Fluorescence emission after FISH hybridization. (A) Ammonia sp., $300 \mu \mathrm{m}$, at optical microscope; (B) Ammonia sp. at optical microscope, displaying pseudopodial activity; (C) Ammonia sp., $460 \mu \mathrm{m}$ from natural sample (Portonovo), hybridization with the S17 probe, umbilical view, high fluorescence signal; (D) Ammonia sp., $300 \mu \mathrm{m}$, from core incubation. FISH hybridization with the S17 probe, low fluorescence signal; (E) Ammonia sp., $300 \mu \mathrm{m}$, from core incubation. FISH hybridization with the S17 probe, high fluorescence signal; (F) Ammonia sp. $460 \mu \mathrm{m}$, Portonovo, ventral view. FISH hybridization with the S17, high fluorescence signal; (G) Eggerella scabra, 400 $\mu \mathrm{m}$, from culture maintenance. FISH hybridization with the S17 probe, low fluorescence signal; (H) Eggerella scabra, $430 \mu \mathrm{m}$, from core incubation. FISH hybridization with the EUK 1209R probe, low fluorescence signal; (I) Eggerella scabra, $430 \mu \mathrm{m}$, natural sample (Portonovo). FISH hybridization with the EUK 1209R probe, low fluorescence signal; (L) Psammophaga sp., $350 \mu$ m, from culture maintenance. FISH hybridization with the S17 probe, low fluorescence signal; (M) Psammophaga sp., $270 \mu \mathrm{m}$, and Psammophaga sp., $300 \mu \mathrm{m}$, from culture maintenance. FISH hybridization with the S17 probe, low fluorescence signal; (N) Silver saccamminid sp, $280 \mu \mathrm{m}$, from culture maintenance. FISH hybridization with the S17 probe, low fluorescence signal; (O) Leptohalysis scottii, $650 \mu \mathrm{m}$, from natural sample (Portonovo). FISH hybridization with the EUK 1209R probe, low fluorescence signal; (P) Leptohalysis scottii, $800 \mu$ m, from natural sample (Portonovo). FISH hybridization with the EUK 1209R probe, high fluorescence signal: (Q) Miliolids organism, $600 \mu \mathrm{m}$, from natural sample (Portonovo). FISH hybridization with the S17 probe, low fluorescence signal; (R) Miliolids organism, $620 \mu \mathrm{m}$, from natural sample (Portonovo). FISH hybridization with the S17 probe, high fluorescence signal. 
Table 1. Results of optical microscopy (OM) observations performed on different taxonomic groups from different samples. Active = individuals that displayed pseudopodial activity; inactive = individuals that did not show pseudopods. Inactive individuals may be alive but in a quiescent state (based on cytoplasmatic color, presence of sediment in front of the aperture and presence of pigments inside the cell). See text for details.

\begin{tabular}{|c|c|c|c|}
\hline \multicolumn{4}{|c|}{ (a) Organisms from culture maintenance } \\
\hline Taxonomic group & \# organisms & \# orgamisms active & \# organisms inactive \\
\hline Ammonia group & 20 & & 20 \\
\hline Miliolids & 17 & & 17 \\
\hline Agglutinated polythalamous taxa & 5 & 1 & 4 \\
\hline Soft-shelled monothaloamous taxa & 5 & 1 & 4 \\
\hline Total & 47 & 2 & 45 \\
\hline \multicolumn{4}{|l|}{ (b) Organisms from core incubation } \\
\hline Taxonomic group & \# organisms & \# orgamisms active & \# organisms inactive \\
\hline $\begin{array}{l}\text { Ammonia group } \\
\text { Miliolids }\end{array}$ & 3 & 3 & \\
\hline $\begin{array}{l}\text { Agglutinated polythalamous taxa } \\
\text { Soft-shelled monothaloamous taxa }\end{array}$ & 2 & & 2 \\
\hline Total & 5 & 3 & 2 \\
\hline \multicolumn{4}{|l|}{ (c) Organisms from natural samples } \\
\hline Taxonomic group & \# organisms & \# orgamisms active & \# organisms inactive \\
\hline Ammonia group & 10 & 4 & 6 \\
\hline Miliolids & 18 & 8 & 10 \\
\hline Agglutinated polythalamous taxa & 11 & 5 & 6 \\
\hline Soft-shelled monothaloamous taxa & 6 & 1 & 5 \\
\hline Total & 45 & 18 & 27 \\
\hline
\end{tabular}

The first step was to extract individual organisms (Fig. 1). We considered specimens as "active" on the basis of the presence of detectable pseudopodial activity under an optical microscope (OM) provided with a phase contrast objective. In the absence of any pseudopodial activity, we assessed the cytoplasm color (from yellow to light brown, de Nooijer et al., 2009) given by the presence of algal pigments (de Nooijer et al., 2008; Filippson et al., 2010) and the occurrence of sediment material at the aperture proximity and/or covering the test. Individuals with these features were considered "potentially alive but inactive" (Table 1). Otherwise, cells that did not show any of these features were considered as "dead". One to five specimens of foraminifera were placed in a concave slide for taxonomic identification. Water was removed from the slide and the specimens fixed with $50 \mu \mathrm{l}$ of phosphate-buffered saline (PBS) and ethanol $\left(1: 1 \mathrm{vol} \mathrm{vol}^{-1}\right)$. No formaldehyde was used because of its potentially negative effects on the hybridization procedure, such as possibly resulting in a reduced permeability to oligonucleotide probes (Hugenholtz et al., 2001). Fixed samples were immediately analyzed or, when this was impossible, stored at $-20^{\circ} \mathrm{C}$ for up to one week. For the hybridization protocol, the PBS:ethanol mixture was removed by exposure to LAF (Laminar Air Flow) for a few minutes. In this way, ethanol could be removed without negatively affecting the FISH results. Then, $40 \mu \mathrm{l}$ of a mixture $\left(9: 1 \mathrm{vol} \mathrm{vol}^{-1}\right)$ of hybridization buffer $[5 \mathrm{M} \mathrm{NaCl}, 1 \mathrm{M}$ Tris $/ \mathrm{HCl}, 35 \%$ formamide and

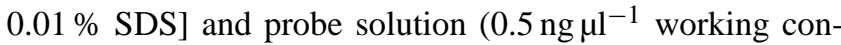
centration) was added. The percentage of formamide was chosen based on literature data (for the EUK 1209R probe; Stoeck et al., 2003) and on the results of preliminary experiments carried out for the definition of the optimal stringency for the probe S17. All probes (including non-sense probes) had been previously labeled at the $5^{\prime}$ end with the fluorescent molecule Cy-3 (Eurofins MWG Operon). After hybridization, slides were placed into a Petri dish and put into a dark incubation chamber. Within the Petri dishes, we also placed a small piece of a paper towel soaked with $1 \mathrm{ml}$ of hybridization buffer, to prevent buffer evaporation from the samples. Hybridization times varied from 1.5 to $3 \mathrm{~h}$ at $46^{\circ} \mathrm{C}$. After incubation, the hybridization mixture was removed and $200 \mu \mathrm{l}$ of pre-warmed $\left(46^{\circ} \mathrm{C}\right)$ washing buffer $[5 \mathrm{M}$ 
$\mathrm{NaCl}, 1 \mathrm{M}$ Tris/HCl, 0.5M EDTA, $0.01 \% \mathrm{SDS}]$ were added. The slides were incubated at $48^{\circ} \mathrm{C}$ for $15 \mathrm{~min}$ and then the solution carefully removed using a pipette. After that, slides were rinsed with sterile milliQ water and then dried under LAF. Finally, slides were observed under an epifluorescence microscope (Zeiss Axioskop 2, at 100X magnification) using an appropriate filter set for Cy-3.

In order to differentiate fluorescence emission among cells, digital images of hybridized foraminifera were acquired, with fixed settings and no scaling, using a Lumix TZ-65 10.1 megapixels digital camera (Panasonic) attached to the epifluorescence microscope. This approach was similar to that already used for measuring the uptake rates of fluorescent bacteria by foraminifera (Langezaal et al., 2005). Then, we estimated the fluorescence emission as the level of brightness of each picture by constructing a scale of fluorescence (Fig. 3).

Initially, we performed tests to verify the suitability of FISH protocol on foraminiferal cells. While FISH is routinely used to analyze prokaryotic and other eukaryotic microrganisms, it has never been applied to foraminifera. This made it necessary to perform tests to verify the applicability of FISH to this group of unicellular organisms.

First, foraminiferal individuals were examined under epifluorescence microscopy for autofluorescence (i.e., without any probe addition) in order to exclude that some cellular components (e.g., photosynthetic pigments, cofactor F420 and some proteins) displayed autofluorescence (Fig. 1). This could lead to potential artifacts or misinterpretations in the analysis of FISH fluorescence (Hugenholtz et al., 2001), as it might make uncertain the actual source of fluorescence. Several good-looking organisms, randomly chosen (4 individuals for Ammonia group, Miliolids individuals and agglutinated polythalamous taxa), were checked under epifluorescence microscopy and under the filter set appropriate for the fluorochrome Cy-3 utilized for FISH. Autofluorescence is known for a wide range of prokaryotic and eukaryotic organisms, including nematodes, phytoplankton cells and stony corals (Booth, 1987; Forge and MacGuidwin, 1989; Ainsworth et al., 2006). Our results revealed that all specimens of all foraminiferal groups showed null or extremely weak autofluorescence under the filter set used for Cy-3 detection, suggesting that autofluorescence was not a source of bias in FISH analysis of foraminifera.

Second, we tested the FISH protocol on dead foraminifera from both experimental sets and natural sediment samples, in order to verify the possible fluorescence emission by dead cells or by empty tests containing detrital cytoplasmatic remains (Fig. 1). This fluorescence emission could be the result of probe unspecific hybridization with the inner organic layer of the shell, the protoplasm and other organic residues of recently-dead organisms (Weiner and Erez, 1984; Bentov and Erez, 2006). To do this, we applied a washing procedure to kill cells and to remove the organic matrix. We incubated cells from one to two hours in $3 \% \mathrm{NaClO}$ and, after that, we washed them in deionised water (7 steps). The washed shells were also observed under a SEM microscope which, because of the high magnification, allowed testing the effectiveness of the washing protocol in removing the organic component(s) of the test. In this framework, 3 individuals from Ammonia group and 2 from Miliolids were hybridized with EUK 1209R probe while, 4 Ammonia group individuals and 3 Miliolids organisms were tested with the foraminiferal specific S17 one (Fig. 2). SEM observations provided us evidence that this protocol was highly efficient in removing all cytoplasmatic remains in both groups. The emission of fluorescence was null or, when detectable, extremely low and therefore indistinguishable from the background fluorescence. Only in one case, one organism belonging to Miliolids when hybridized with the S17 probe, displayed a fluorescent signal evident only along the shell edge. This signal could be caused by an inefficiency in the removal of the residual organic matter (along the perimeter of the inner chambers of the test, where the fluorescence signal was localized) with the washing procedure described above. Due to this result, the procedure was modified by increasing the incubation time in $3 \% \mathrm{NaClO}$ from 1 to $2 \mathrm{~h}$. We doubled the time of Na$\mathrm{ClO}$ treatment to obtain a more efficient removal of organic residues from shells. This procedure allowed eliminating any fluorescent signal in the two dead Miliolids specimens subsequently analyzed. An important step for the optimization of the protocol was to further demonstrate that shells and their organic components did not hybridize with probes and to verify that tests were not a barrier for probes permeation. For this reason, 12 specimens (6 individuals from Ammonia group and 6 from Miliolids) were incubated in EDTA 0.1M for $36 \mathrm{~h}$, according to the protocol described in Le Cadre and Debenay (2006), then hybridized using both probes (Fig. 1). The result of our experiment clearly showed that the shell and its organic components did not hybridize with probes and therefore verifies that the test did not hamper the probe penetration inside the cell, and that the fluorescence was not the result of the unspecific hybridization between probes and organic components of the foraminiferal test (Fig. 2).

The steps discussed above allowed us to establish a FISH protocol that was unbiased by false positives. The results of the analyses performed after optimization are shown in the following paragraph.

\subsection{Statistical analyses}

The Chi-squared 2-sample test with Yates continuity correction was utilized to test for differences between the FISH results obtained with the two probes (EUK 1209R and S17). The test was performed using the software R 2.11.1. The Ttest for paired data was performed to test differences in the numbers of specimens classified as "active" and "inactive" by optical microscopy and FISH analysis for each taxonomical group. 


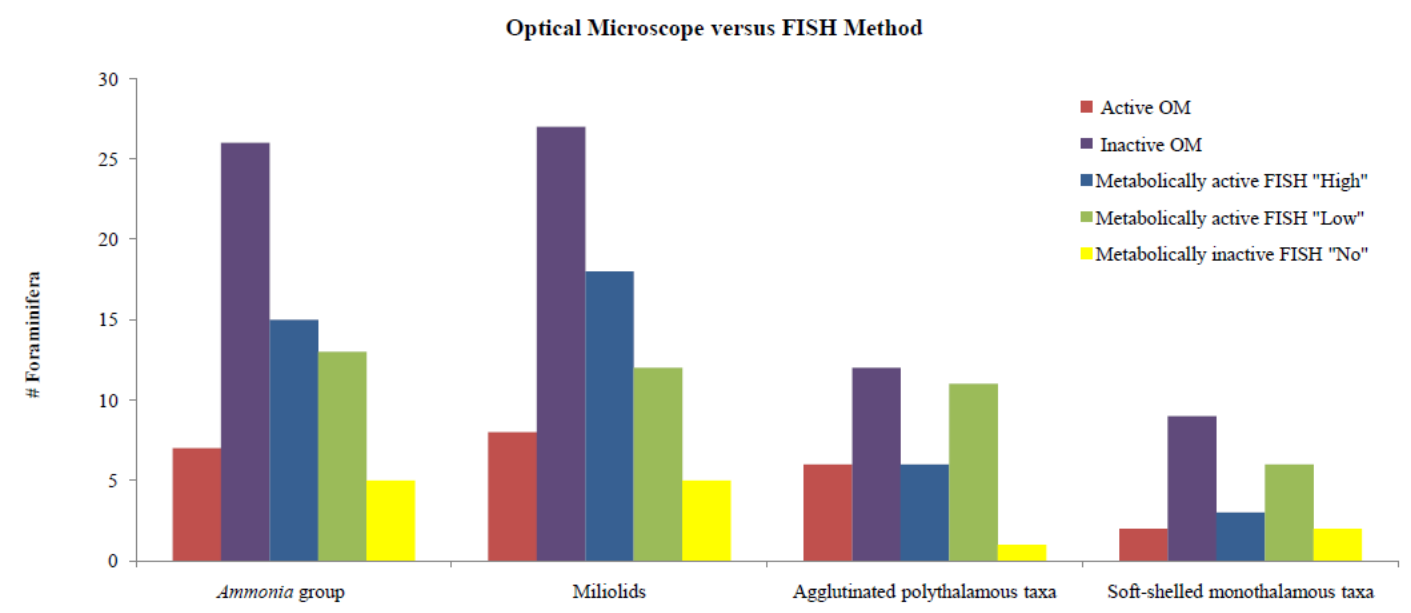

Fig. 4. Comparison between $\mathrm{OM}$ and FISH efficiency. "Active" $\mathrm{OM}=$ individuals that displayed pseudopodial activity; "inactive" $\mathrm{OM}=$ individuals that did not show pseudopods but, on the basis of cytoplasmatic color, presence of sediment in front of the aperture and of pigments inside the cell, may be alive but in a quiescent state. "Metabolically active" FISH=individuals that emitted fluorescence, reported as low or high basing on the signal intensity; "metabolically inactive" FISH = individuals that did not emit any visible fluorescence.

Table 2. Results of FISH analyses performed on different taxonomic groups. Comparison between EUK 1209R and S17 probe results. See text for details.

\begin{tabular}{|c|c|c|c|c|c|c|c|}
\hline Taxonomic group & \# specimens & $\begin{array}{c}\text { \# specimens tested } \\
\text { with EUK 1209R } \\
\text { probe }\end{array}$ & $\begin{array}{l}\text { \# specimens FISH } \\
\text { fluorescence with } \\
\text { EUK 1209R probe }\end{array}$ & $\begin{array}{l}\% \text { stained } \\
\text { specimens }\end{array}$ & $\begin{array}{l}\text { \# specimens } \\
\text { tested with } \\
\text { S17 probe }\end{array}$ & $\begin{array}{l}\text { \# specimens FISH } \\
\text { fluorescence } \\
\text { with } \mathrm{S} 17 \text { probe }\end{array}$ & $\begin{array}{l}\% \text { stained } \\
\text { specimens }\end{array}$ \\
\hline Ammonia group & 33 & 19 & 17 & 89 & 14 & 11 & 79 \\
\hline Miliolids & 35 & 25 & 22 & 88 & 10 & 8 & 80 \\
\hline Agglutinated polythalamous taxa & 18 & 9 & 7 & 78 & 9 & 8 & 89 \\
\hline Soft-shelled monothalamous taxa & 11 & 3 & 3 & 100 & 8 & 6 & 75 \\
\hline Total & 97 & 56 & 49 & 88 & 41 & 33 & 80 \\
\hline
\end{tabular}

\section{Results: application of FISH protocol}

Because it is impossible testing, on the same organism, FISH and any other techniques that imply the use of dyes or probes, we decided to compare our FISH protocol with the optical microscopy. For this reason, the first step has been the observation of all the organisms, belonging to different taxonomic groups from different samples (culture maintenance, core incubation and natural sediment samples), under an optical microscope. Results are shown in Table 1. The organisms were classified as "active" and "inactive" under the optical microscope $(\mathrm{OM})$, based on the characteristics described in the Materials and Methods section. All 20 individuals belonging to the Ammonia group from our culture maintenance setting were considered "inactive" under the optical microscope (Table 1a), while the 3 organisms from core incubation samples, which showed pseudopodial activity, were classified as "active" (Table 1b). Finally, 4 of the 10 individuals from the natural sediment samples were "active" and 6 were "inactive" (Table 1c). In the Miliolids group, all 17 indi- viduals from the culture maintenance were "inactive". Conversely, 8 of the 18 organisms from natural sediment samples were classified as "active" and 10 as "inactive" (Table 1c). Five agglutinated taxa cells from culture sets (Table 1a), all belonging to the species Eggerella scabra, were also analyzed ( 1 was "active" and 4 were "inactive", Table 1a). The 2 organisms from the core incubation also were "inactive" (Table 2b). From natural samples, 11 agglutinated individuals (belonging to Eggerella scabra and Leptohalysis scottii species) were picked. Five were classified as "active" and 6 as "inactive" (Table 1c). Finally, only one of the 5 softshelled monothalamous organisms (i.e., Psammophaga sp.) from the culture sets was "active", while the others were "inactive" and did not show any pseudopodial activity (Table 1a). From natural samples, only 1 of the 6 soft-shelled monothalamous organisms (Psammophaga sp. and saccamminid morphotypes) showed pseudopodial activity and was "active", while the other 5 were classified as "inactive" (Table 1c; Fig. 4). All these individuals were subsequently analyzed by FISH (Fig. 1). 
We performed our FISH protocol on a total of 97 individuals (Table 2), which were representative of the foraminiferal groups Ammonia, Miliolids, agglutinated polythalamous and soft-shelled monothalamous taxa. In detail, FISH protocol was performed on 33 specimens of Ammonia group (Table 2); 19 of them were tested using EUK 1209R probe and, of these, 17 emitted fluorescence. The remaining 14 were tested using the specific foraminiferal probe $\mathrm{S} 17$ and 11 emitted fluorescence. Among the 35 individuals of Miliolids assayed (Table 2), 25 were hybridized with EUK 1209R and 22 emitted fluorescence, while eight out of ten, hybridized with S17, emitted fluorescence. For agglutinated polythalamous taxa, 18 organisms were hybridized, nine with EUK 1209R and nine with S17. After hybridization with EUK 1209R probe, seven emitted fluorescence while only one out of the nine assayed with the S17 probe did not result in a fluorescence signal. Among soft-shelled monothalamous taxa, all the three individuals tested with EUK 1209R emitted fluorescence, while six out of eight cells assayed with S17 emitted fluorescence.

Table 2 shows the percentages of cells which produced a positive FISH signal using the two probes (the universal eukaryotic EUK 1209R and the foraminiferal-specific S17). The probes showed a comparable efficiency in staining living individuals. In particular, the percentage of cells stained ranged from 78 to $100 \%$ using the EUK $1209 \mathrm{R}$ probe and from 75 to $89 \%$ with the S17 probe (Table 2). The chisquared 2-sample test with Yates continuity correction, performed to test differences between the results obtained using the probes EUK 1209R and S17 revealed that the results obtained with the two probes were not significantly different (p-value $>0.05$ ).

Table 3 reports the results of the FISH analyses performed on the organisms described in Table 1, and interpreted using a fluorescence scale (as reported in Fig. 3). This procedure allowed us to distinguish, based on the different fluorescence emission, between "metabolically active" (low to high fluorescence) and inactive (no fluorescence) individuals (Fig. 3 and Fig. 4). Based on this fluorescence scale, cells that did not show any fluorescence signal or displayed background fluorescence were classified as "inactive" (Table 3; Fig. 4). Organisms with a low fluorescence emission after FISH hybridization were classified as "metabolically active" but in a quiescent state (low activity), while organisms that showed high fluorescence were judged as "metabolically active" (high activity). The results clearly highlight that this classification of metabolically active/inactive state based on the fluorescence signal after hybridization is different from the one obtained using the optical microscope. Five of the 26 Ammonia group individuals, from natural samples and culture, classified as "inactive" under the optical microscope, did not emit fluorescence, while nine emitted a strong fluorescence signal, indicating potentially intense metabolism; the other 12 cells displayed a low fluorescence (Table 3). Conversely, six of the seven Ammonia group organisms, clas- sified as "active" under the optical microscope, showed a strong fluorescence, while only one showed a low fluorescence signal (low metabolic activity). Five of the 27 inactive Miliolids did not show any fluorescence, while ten exhibited a very strong fluorescence signal. The remaining 12 organisms had a low fluorescence emission (Table 3). However, all eight cells classified as "active" using microscope observations yielded "metabolically active" using FISH analysis. Among the 12 agglutinated individuals classified as "inactive" under optical microscope, one did not emit fluorescence and nine showed low fluorescence emission (probably corresponding to a quiescent/dormant state); 2 were "metabolically active", displaying a strong fluorescence signal (Table 3). Among the other six agglutinated individuals, classified as "active" by optical microscopy, four were classified as "metabolically active" also using FISH, while two showed a low fluorescence emission. Finally, 11 soft-shelled monothalamous specimens were analyzed. Two organisms of the nine classified as "inactive", from natural samples, did not show fluorescence; six showed a low fluorescence signal, (low metabolic activity), while the remaining one (Saccamminid sp. 8) displayed an intense fluorescence (high metabolic activity). The two Psammophaga sp. specimens from natural and culture maintenance samples, previously classified as "active", also displayed intense fluorescence (high metabolically activity).

Even if cells showed comparable intensities of fluorescence emission, there were some differences among the different taxonomic groups. In both the Ammonia group and Miliolids specimens, the fluorescence was apparently homogeneous in the cell protoplasm even if, in some instances in the Ammonia group, the fluorescence was concentrated in the last chamber or in the first ones (Fig. 3e). In case of Miliolids, the fluorescence was highest along the edge of the shell. This signal was different from that observed in one case after the washing procedure during the optimization of our FISH protocol. In fact, in that case the fluorescence was localized just along the perimeter of the test and not inside the cell, while the signal registered on living organisms was homogeneous in the cell, strongest along the edge of the shell. Also in agglutinated polythalamous foraminifera, the fluorescence appeared weaker and quite homogeneously distributed within the organisms (Fig. 3i, p) while, in soft-shelled monothalamous individuals, the fluorescence signal was more localized in different regions of the cell (Fig. 3m). We can not exclude that a difference in shell composition could bias the fluorescence emission. However, it is evident that there is clear variability of fluorescence emission due to the different conditions. This means that the main signal is well recognizable, and this issue in not really affecting our results.

Optical microscopy ("active" vs. "inactive" organisms) and FISH (null, low and high fluorescence) analyses yield different results (Fig. 4; Tables 1 and 3). The number of specimens considered "inactive" after OM was 74 , while those classified "inactive" after FISH were 13 (as sum of 
Table 3. Classification of fluorescence emission after FISH hybridization performed on organisms belonging to different taxonomic groups (already shown in Tables 1 and 2). No=no fluorescence emission; low = weak fluorescence emission; high=strong fluorescence emission. Fluorescence intensity was used as an index of metabolic activity (inactive vs. active). See text for details.

\begin{tabular}{lcccc}
\hline & & \multicolumn{3}{c}{ Level of fluorescence } \\
\cline { 3 - 5 } Taxonimic group & \# organisms & $\begin{array}{c}\text { Inactive } \\
\text { No }\end{array}$ & $\begin{array}{c}\text { Active } \\
\text { Low }\end{array}$ & $\begin{array}{c}\text { Active } \\
\text { High }\end{array}$ \\
\hline Ammonia group & 33 & 5 & 13 & 15 \\
Miliolids & 35 & 5 & 12 & 18 \\
Agglutinated polythalamous taxa & 18 & 1 & 11 & 6 \\
Soft-shelled monothalamous taxa & 11 & 2 & 6 & 3 \\
\hline Total & 97 & 13 & 42 & 42 \\
\hline
\end{tabular}

individuals from all taxonomic groups). The T-test for paired data performed on numbers of specimens detected as "inactive" by optical microscopy and FISH analysis, for each taxonomic group, revealed significant differences ( $\mathrm{p}$ value $<0.05$ ) between the two techniques. The metabolically inactive (no fluorescence) individuals detected by FISH were significantly lower ( $\mathrm{p}$-value $<0.05$ ) than those revealed by optical microscopy.

\section{Discussion}

Fluorescent in situ hybridization has been widely utilized for a decade for the identification of living bacteria and archaeal cells in a variety of habitats, including marine sediments and soils (Karner and Fuhrman, 1997; Christensen et al., 1999). As emphasized in Kerkhof and Ward (1993) and Smith and del Giorgio (2003), the capacity of FISH to detect metabolically active bacterial cells is related to the cellular rRNA content, widely recognized as an index of cellular activity (Karner and Fuhrman, 1997). In addition, due to the employment of taxonomic-specific probes, FISH allows to distinguish bacterial and archaeal cells belonging to different taxonomic groups (Hugenholtz et al., 2001). FISH also has been used on several eukaryotic protists, such as ciliates, flagellates and mixed protists assemblages (Lim et al., 1993, 1996; Fried at al., 2002), with different purposes and results. For example, Lim et al. (1996) utilized FISH as a quantitative method for examining natural assemblages of protists; Fried at al. (2002) used fluorescent in situ hybridization, together with silver stain technique, to improve ciliate identification and counting; Medlin and Kooistra (2010) recently reported FISH as a useful tool to estimate the diversity in marine photosynthetic protist communities. This molecular technique has shown promising results also in detecting the metabolically active fraction of organisms in assayed samples. The results of Lim et al. (1993), who applied rRNA-based probes in the observation of marine nanoplanktonic protists, clearly showed that the hybridization was different in cells under dif- ferent physiological states. In particular, they showed that a very strong signal after hybridization of cells in early to midlogaritmic phase of growth (when it is assumed that cells are under an intense metabolic activity), while a weaker signal was typical in cells in stationary growth (when the metabolic activity is reduced; Lim et al., 1993).

Based on the success of FISH in other groups, we tested its ability to detect metabolically active foraminifera, and to discern between different metabolic statuses. Because the rRNA cellular content is known to be proportional to the growth rate of a cell (DeLong et al., 1989), we expected that the physiological condition of foraminiferal cells would affect the amount of probe-bound signal and consequently the intensity of the hybridization signal. We hypothesized that nourished individuals are more active than starved and/or stressed ones, and thus, nourished individuals should emit a higher fluorescence signal as a result of a higher number of active ribosomes in the cells (which are busy in synthesizing proteins to sustain cell growth). To test this hypothesis, we used assayed foraminifera from different experimental sets (i.e., culture maintenance and core incubation) and from natural samples, as described above. Our results clearly indicate that the FISH approach discriminates different metabolic status of cells through a gradient in the fluorescence emission, and without any statistical differences between the universal eukaryotic probe (EUK 1209R) and the foraminiferalspecific probe (S17). Our results are similar to those published in Eller et al. (2007), where the authors show the use of specific probes to characterize phytoplankton samples targeting different taxonomic groups belonging to Haptophyta and Heterokonta. After they tested several new probes to detect organisms at different taxonomic levels, they found that the signal with specific probes showed an intensity that was comparable to that of the universal eukaryotic probe EUK $1209 R$.

In addition, our results show that FISH provides the means to discern different physiological statuses (from low to high), thus providing a more detailed and robust way to distinguish 
between active and inactive organisms when compared to optical microscopy. All the organisms, classified as "active" under the OM (basing on their visible pseudopodia), were classified as "metabolically active" also using FISH and showed a high fluorescence signal. Only in three cases (one individual belonging to Ammonia group and two individuals belonging to agglutinated polythalamous taxa), organisms showing pseudopodial activity displayed a low fluorescence intensity after FISH hybridization, which may suggest low metabolic activity but not complete dormancy of the cell. We thus can hypothesize that the low fluorescence may be the result of stress to the cell during manipulation for FISH analyses. These results, if true, highlight the high sensitivity of FISH in detecting also short-term changes in the cellular metabolic status. However, if excluding the three cases of low fluorescence in those organisms showing pseudopodial activity, the hybridization results from all the other "active" organisms assayed with FISH hybridization underline that the FISH does not produce false negative results.

However, our results showed that the use of only OM may lead to an over-estimation of inactive cells. Indeed, the number of specimens considered "inactive" after optical microscopy (74) is significantly higher than those classified "inactive" after FISH (13). This important difference is possibly a consequence of the capability of the FISH protocol to discriminate among those organisms claimed as "inactive" under the optical microscope based on the absence of pseudopodial activity and those that were metabolically active (high or low fluorescence signal). This was observed in 9 organisms belonging to the Ammonia group, 10 Miliolids, two individuals belonging to agglutinated polythalamous taxa and 1 to soft-shelled monothalamous taxa. These results may be evidence that the lack of visible pseudopodial activity per se does not mean complete metabolic inactivity of the cell (de Nooijer et al., 2008). For these reasons, the FISH protocol developed here could represent an innovative and complementary procedure to those traditionally utilized, e.g., Rose Bengal staining, FDA and BCECF-AM probes, MTT salt and CellTracker Green.

Rose Bengal is a cheap, easy and fast procedure, resulting useful for environmental sample analysis but it is well known to be not completely reliable for the staining of recently dead cells, because remnants of tissues may remain preserved (and thus stainable) for a long time within dead animals (Murray and Bowser, 2000). As such, since the Rose Bengal binds proteins and other macromolecules, the potential for generating false positive cells is quite high. Rose Bengal remains the cheaper and faster method to grossly evaluate the live/dead proportions in a foraminiferal assemblage, but the Rose Bengal stain does not provide detailed and accurate information on the metabolic status of cells. The salt MTT, analogous to Rose Bengal staining, does not provide information on the metabolic activity of the organisms. In addition, this approach could produce false positives and needs the use of antibiotics to stop bacterial activity that also could cause staining of dead organisms (de Nooijer et al., 2006). Other approaches to detect metabolically active foraminifera are based on fluorogenic probes (e.g., diacetates of fluorescein FDA- and AM-esters of biscarboxyethylcarboxyfluorescein - BCECF-AM-; Bernhard et al., 1995) that measure both enzymatic activity (required to activate their fluorescence) and cell-membrane integrity. The limit of these probes is the duration of postmortem enzymatic activity, which imposes some limitations in the experimental design (Bernhard et al., 1995). This issue might represent a potential problem for another widely-utilized probe, the CellTracker Green CMFDA (CTG) that can be applied to both unicellular and multicellular marine organisms (Danovaro et al., 2010). Even if it has the advantage of being a "non-terminal method" (Bernhard et al., 1995; Pucci et al., 2009), the CTG-generated fluorescence can be masked by other sources of fluorescence, such as the presence of bacterial stocks or nematodes living inside the foraminiferal shell (Pucci et al., 2009). In this context, the FISH protocol could add more information to that obtained using the other techniques mentioned above. In fact, this molecular technique permits discrimination between active and inactive cells, due to the detection of their rRNA content, and to assess different metabolic states of each cell. The high lability of rRNA is expected to exclude staining events even after a recent cell death, potentially reducing the possibility of false positives.

\section{Conclusions}

We propose the FISH as a complementary technique, which distinguishes between different metabolic conditions (as low and high fluorescence) and detects quiescent/dormant cells. Our study shows that this technique is reliable and does not generate false positive results (i.e., detection of a fluorescence signal from totally inactive cells). This characteristic offers the possibility to use FISH in the framework of short-term experimental studies, where postmortem persistence of enzymatic activity can introduce a potential bias if traditional viability techniques are used. Possible applications of the FISH technique include the evaluation of the physiological response following ecotoxicological or dietary experiments, and the detection of short-term changes in the foraminiferal metabolic status. As an additional advantage, FISH does not require laboratory-intensive incubations with antibiotics (as needed for MTT staining, for example) and allows sample storage at $-20^{\circ} \mathrm{C}$ for later analysis, after the picking of organisms and the fixation step (with PBS and ethanol). However, one disadvantage of FISH, along with the necessity of expensive facilities (i.e., epifluorescence microscope), is its difficulty to be used as screening procedure for large volumes of sediment. For this reason, FISH does not represent an alternative tool to those traditionally utilized in studies of foraminiferal ecology; rather, it is a complementary molecular technique that is useful in cases in which other 
techniques may fail. The conditions and species used in this study are obviously not representative of all natural conditions and foraminiferal species. Future studies applying this methodology will add more data to validate it. However, it is important to highlight the potential of this technique to study foraminiferal physiology and ecology, with applications both in natural and experimental settings.

Acknowledgements. This work was partially supported by HERMES - Hotspot Ecosystem Research on the Margins of European Seas (contract number GOCE-CT-2005-511234), funded by the European Commission's Framework Six Programme and HERMIONE - Hotspot Ecosystem Research and Man's Impact on European Seas (contract number 226354) funded by the European Commission's Framework Seven Programme and by FAR 2010 funding to A.N. The authors gratefully acknowledge Irene Pancotti for support in foraminiferal analysis; Silvia Bianchelli, Antonio Dell'Anno and Antonio Pusceddu (Polytechnic University of Marche) for precious advices on an early draft of the manuscript. Miriam E. Katz (Rensselaer Polytechnic Institute) for her help in editing the text and J.-P. Gattuso, L. de Noojier and three anonymous referees provided constructive feedback that greatly helped to improve the manuscript. C.B. gratefully thanks also the Cushman Foundation for the Cushman Foundation Student Travel Award for Forams 2010.

\section{Edited by: J. Middelburg}

\section{References}

Ainsworth, T. D., Fine, M., Blackall, L. L., and Hoegh-Guldberg, O.: Fluorescence in situ hybridization and spectral imaging of coral-associated bacterial communities, Appl. Environ. Microb., 72, 3016-3020, 2006.

Bentov, S. and Erez, J.: Impact of biomineralization processes on the $\mathrm{Mg}$ content of foraminiferal shells: a biological perspective, Geochem. Geophy. Geosy., 7, Q01P08, doi:10.1029/2005GC001015, 2006.

Bernhard, J. M.: Distinguishing live from dead foraminifera: methods review and proper applications, Micropaleontology, 46, 3846, 2000.

Bernhard, J. M., Newkirk, S. G., and Bowser, S. S.: Towards a nonterminal viability assay for foraminiferan protists, J. Eukaryot. Microbiol., 42, 357-367, 1995.

Bernhard, J. M., Blanks, J. K., Hintz, C. J., and Chandler, G. T.: Use of the fluorescent calcite marker calcein to label foraminiferal tests, J. Foramin. Res., 34, 96-101, 2004.

Bernhard, J. M., Ostermann, D. R., Williams, D. S., and Blanks, J. K.: Comparison of two methods to identify live benthic foraminifera: a test between Rose Bengal and CellTracker Green with implications for stable isotope paleoreconstructions, Paleoceanography, 21, PA4210, doi:10.1029/2006PA001290, 2006.

Bernhard, J. M., Sen Gupta, B. K., and Baguley, J. G.: Benthic foraminifera living in Gulf of Mexico bathyal and abyssal sediments: community analysis and comparison to metazoan meiofaunal biomass and density, Deep-Sea Res. Pt. II, 55, 2617-2626, doi:10.1016/j.dsr2.2008.07.011, 2008.

Booth, B. C.: The use of autofluorescence for analyzing oceanic phytoplankton communities, Bot. Mar., 30, 101-108, 1987.
Christensen, H., Hansen, M., and Sørensen, J.: Counting and size classification of active soil bacteria by Fluorescence In Situ Hybridization with an rRNA oligonucleotide probe, Appl. Environ. Microb., 65, 1753-1761, 1999.

Danovaro, R., Corinaldesi, C., Luna, G. M., Magagnini, M., Manini, E., and Pusceddu, A.: Prokaryote diversity and viral production in deep-sea sediments and seamounts, Deep-Sea Res. Pt. II, 56, 738-747, 2009.

Danovaro, R., Dell'Anno, A., Pusceddu, A., Gambi, C., Heiner, I., and Kristensen, R. M.: The first 30 metazoa living in permanently anoxic conditions, BMC Biol., 8, 2010.

DeLong, E. F., Wickham, G. S., and Pace, N. R.: Phylogenetic strains: ribosomial RNA-based probes for the identification of single cells, Science, 243, 1360-1363, 1989.

De Nooijer, L. J., Duijnstee, A. P., and Van der Zwaan, G. J.: Novel application of MTT reduction: a viability assay for temperate shallow-water benthic foraminifera, J. Foramin. Res., 36, 195200, 2006.

De Nooijer, L. J., Toyofuku, T., Oguri, K., Nomaki, H., and Kitazato, H.: Intracellular $\mathrm{pH}$ distribution in foraminifera determined by the fluorescent probe HPTS, Limnol. Oceanogr.-Meth., 6, 610-618, 2008.

De Nooijer, L. J., Langer, G., Nehrke, G., and Bijma, J.: Physiological controls on seawater uptake and calcification in the benthic foraminifer Ammonia tepida, Biogeosciences, 6, 26692675, doi:10.5194/bg-6-2669-2009, 2009.

De Stigter, H. C., Jorissen, F. J., and Van der Zwaan, G. J.: Bathymetric distribution and microhabitat partitioning of live (Rose Bengal stained) benthic Foraminifera along a shelf to bathyal transect in the southern Adriatic Sea, J. Foramin. Res., 28, 40$65,1998$.

Dupperon, S., Nadalig, T., Caprais, J. C., Sibuet, M., Fiala-Médioni, A., Amann, R., and Dubilier, N.: Dual symbiosis in a Bathymodiolus sp. mussel from a methane seep on the Gabon continental Margin (Southeast Atlantic): 16S rRNA phylogeny and distribution of the symbionts in gills, Appl. Environ. Microb., 71, 1694$1700,2005$.

Eller, G., Töbe, K., and Medlin, L. K.: Hierarchical probes at various taxonomic levels in the Haptophyta and a new division level probe for the Heterokonta, J. Plankton Res., 29, 629-640, 2007.

Filipsson, H. L., Bernhard, J. M., Lincoln, S. A., and McCorkle, D. C.: A culture-based calibration of benthic foraminiferal paleotemperature proxies: $\delta^{18} \mathrm{O}$ and $\mathrm{Mg} / \mathrm{Ca}$ results, Biogeosciences, 7, 1335-1347, doi:10.5194/bg-7-1335-2010, 2010.

Forge, T. A. and MacGuidwin, A. E.: Nematode autofluorescence and its use as an indicator of viability, J. Nematol., 21, 399-403, 1989.

Frada, M., Not, F., Probert, I., and De Vargas, C.: $\mathrm{CaCO}_{3}$ optical detection with fluorescent in situ hybridization: a new method to identify and quantify calcifying microorganisms from the oceans, J. Phycol., 12, 1162-1169, 2006.

Fried, J., Ludwig, W., Psenner, R., and Heinz, K.: Improvement of ciliate identification and quantification: a new protocol for Fluorescence In Situ Hybridization (FISH) in combination with silver stain techniques, System. Appl. Microbiol., 25, 555-571, 2002.

Garcia-Cuetos, L., Pochon, X., and Pawlowski, J.: Molecular evidence for host-symbiont specificity in soritid foraminifera, Protist, 156, 399-412, 2005. 
Gooday, A. J.: Epifaunal and shallow infaunal foraminiferal communities at three abyssal NE Atlantic sites subject to differing phytodetritus input regimes, Deep-Sea Res. Pt. I, 43, 1395-1421, 1996.

Gooday, A. J., Bett, B. J., Shires, R., and Lambshead, P. J. D.: Deepsea benthic foraminiferal species diversity in the NE Atlantic and NW Arabian Sea: a synthesis, Deep-Sea Res. Pt. II, 45, 165-201, 1998.

Gooday, A. J., Hori, S., Todo, Y., Okamoto, T., Kitazato, H., and Sabbatini, A.: Soft-walled, monothalamous benthic foraminiferans in the Pacific, Indian and Atlantic Oceans: aspects of biodiversity and biogeography, Deep-Sea Res. Pt. I, 51, 33-53, 2004.

Gooday, A. J., Bowser, S. S., Cedhagen, T., Cornelius, N., Hald, M., Korsun, S., and Pawlowski, J.: Monothalamous foraminiferans and gromiids (Protista) from western Svalbard: a preliminary survey, Mar. Biol. Res., 1, 290-312, 2005.

Heinz, P.: Laboratory feeding experiments: response of deep-sea benthic foraminifera to simulated phytoplankton pulses, Revue de Paléobiologie, 20, 643-646, 2001.

Heinz, P., Kitazato, H., Schmiedl, G., and Hemleben, C.: Response of deep-sea benthic foraminifera from the Mediterranean Sea to simulated phytodetritus pulses under laboratory conditions, J. Foramin. Res., 31, 210-227, 2001.

Holzmann, M., Hohenegger, J., Hallock, P., Piller, W. E., and Pawlowski, J.: Molecular phylogeny of larger foraminifera, Mar. Micropaleontol., 43, 57-74, 2001.

Hugenholtz, P., Tyson, G. W., and Blackall, L. L.: Design and evaluation of 16S rRNA-targeted oligonucleotide probes for fluorescence in situ hybridization, in: Methods in molecular biology, Series n. 179. Gene Probes: Principles and Protocols, edited by: Aquino de Muro, M. and Rapley, R., Humana Press Inc., Totowa, NJ, 272 pp., 2001.

Karner, M. and Fuhrman, J. A.: Determination of active marine bacterioplankton: a comparison of universal 16S rRNA probes, autoradiography, and nucleoid staining, Appl. Environ. Microb., 63, 1208-1213, 1997.

Katz, M. E., Tjalsma, R. C., and Miller, K. G.: Oligocene bathyal to abyssal benthic foraminifera of the Atlantic Ocean, Micropaleontology, 49, 1-45, 2003.

Kerkhof, L. and Ward, B. B.: Comparison of nucleic acid hybridization and fluorometry for measurement of the relationship between RNA/DNA ratio and growth rate in a marine bacterium, Appl. Environ. Microb., 59, 1303-1309, 1993.

Langezaal, A. M., Jannink, N. T., Pierson, E. S., and Van der Zwaan, G. J.: Foraminiferal selectivity towards bacteria: an experimental approach using a cell-permeant stain, J. Sea Res., 54, 256-275, 2005.

Le Cadre, V. and Debenay, J.-P.: Morphological and cytological responses of Ammonia (foraminifera) to copper contamination: Implication for the use of foraminifera as bioindicators of pollution, Environ. Pollut., 143, 304-317, 2006.

Lim, E. L., Amaral, L. A., Caron, D. A., and Delong, E. F.: Application of rRNA-based probes for observing marine nanoplanktonic protists, Appl. Environ. Microb., 59, 1647-1655, 1993.

Lim, E. L., Caron, D. A., and Delong, E. F.: Development and field application of a quantitative method for examining natural assemblages of protists with oligonucleotide probes, Appl. Environ. Microb., 62, 1416-1423, 1996.

Medlin, L. K. and Kooistra, W. H. C. F.: Methods to estimate the diversity in the marine photosynthetic protist community with illustrations from case studies, Diversity, 2, 973-1014, 2010.

Mikulski, C. M., Morton, S. L., and Doucette, G. J.: Development and application of LSU rRNA probes for Karenia brevis in the Gulf of Mexico, USA, Harmful Algae, 4, 49-60, 2005.

Morigi, C.: Benthic environmental changes in the Eastern Mediterranean Sea during sapropel S5 deposition, Palaeogeogr. Palaeocl., 273, 258-271, 2009.

Morigi, C., Jorissen, F. J., Fraticelli, S., Horton, B. P., Principi, M., Sabbatini, A., Capotondi, L., Curzi, P. V., and Negri, A.: Benthic foraminiferal evidence for the formation of the Holocene mudbelt and bathymetrical evolution in the central Adriatic Sea, Mar. Micropaleontol., 57, 25-49, 2005.

Murray, J. W.: Ecology and applications of benthic foraminifera, Cambridge University Press, Cambridge (UK), 426 pp., 2006.

Murray, J. W. and Bowser, S. S.: Mortality, protoplasm decay rate, and reliability of staining techniques to recognize 'living' foraminifera: a review, J. Foramin. Res., 30, 66-70, 2000.

Not, F., Simon, N., Biegala, I. C., and Vaulot, D.: Application of fluorescent in situ hybridization coupled with tyramide signal amplification (FISH-TSA) to assess eukaryotic picoplankton composition, Aquat. Microb. Ecol., 28, 157-166, 2002.

Pawlowski, J.: Introduction to the molecular systematic of foraminifera, Micropaleontology, 46, 1-12, 2000.

Pawlowski, J. and Holzmann, M.: Molecular phylogeny of foraminifera - a review, Eur. J. Protistol., 38, 1-10, 2002.

Pernthaler, J., Glöckner, F.O., Schönhuber, W., and Amann, R.: Fluorescence in situ hybridization (FISH) with rRNA-targeted oligonucleotide probes, Method. Microbiol., 30, 207-226, 2001.

Pucci, F., Geslin, E., Barras, C., Morigi, C., Sabbatini, A., Negri, A., and Jorissen, F. J.: Survival of benthic foraminifera under hypoxic conditions. Results of an experimental study using the CellTracker Green method, Mar. Pollut. Bull., 59, 336-351, 2009.

Rice, J., O'Connor, D. C., Sleigh, M. A., Burkill, P. H., Giles, I. G., and Zubkov, M. V.: Fluorescent oligonucleotide rDNA probes that specifically bind to a common nanoflagellate, Paraphysomonas vestita, Microbiology, 143, 1717-1727, 1997a.

Rice, J., Sleigh, M. A., Burkill, P. H., Tarran, G. A., O'Connor, C. D., and Zubkov, M. V.: Flow cytometric analysis of characteristics of hybridization of species-specific fluorescent oligonucleotide probes to rRNA of marine nanoflagellates, Appl. Environ. Microbiol., 63, 938-944, 1997b.

Sabbatini, A., Bonatto, S., Gooday, A. J., Morigi, C., Pancotti, I., Pucci, F., and Negri, A.: Modern benthic foraminifers at Northern shallow sites of Adriatic Sea and soft-walled, monothalamous taxa: a brief overview, Micropaleontol., 56, 359-376, 2010.

Schmiedl, G. and Mackensen, A.: Late Quaternary paleoproductivity and deep water circulation in the Eastern South Atlantic Ocean: evidence from benthic foraminifera, Palaeogeogr. Palaeocl., 130, 43-80, 1997.

Smith, E. M. and del Giorgio, P. A.: Low fractions of active bacteria in natural aquatic communities?, Aquat. Microb. Ecol., 31, 203208, 2003.

Stoeck, T., Fowle, W. H., and Epstein, S. S.: Methodology of protistan discovery: from rRNA detection to quality scanning electron microscope images, Appl. Environ. Microb., 69, 6856-6863, 2003.

Walton, W. R.: Techniques for recognition of living foraminifera. 
Contributions from the Cushman Foundation for Foraminiferal Research, 3, 56-60, 1953.

Weiner, S. and Erez, J.: Organic matrix of the shell of the foraminifer Heterostegina depressa, J. Foramin. Res., 14, 206$212,1984$.
Yokouchi, H., Takeyama, H., Miyashita, H., Maruyama, T., and Matsunaga, T.: In situ identification of symbiotic dinoflagellates, the genus Symbiodinium with fluorescent-labeled rRNA-targeted oligonucleotide probes, J. Microbiol. Meth., 53, 327-334, 2003. 